\title{
Evaluation of Multifidus Muscle Atrophy in MRI Images of Patients with Spinal Pain and its Related Factors
}

\author{
Ahmad Rezaei Azandariani', Azar Pirdehghan², Maryam Varmaghani3,**iD \\ ${ }^{I}$ Assistant Professor, Department of Radiology, School of Medicine, Hamadan University of Medical Sciences, Hamadan, \\ Iran \\ ${ }^{2}$ Associate Professor, Department of Social Medicine, School of Medicine, Hamadan University of Medical Sciences, \\ Hamadan, Iran \\ ${ }^{3}$ Resident, Department of Radiology, School of Medicine, Hamadan University of Medical Sciences, Hamadan, Iran \\ * Corresponding Author: Maryam Varmaghani, Department of Radiology, School of Medicine, Hamadan University of \\ Medical Sciences, Hamadan, Iran. Email: m.varmaghani1990@gmail.com
}

Received: 25.10 .2019

Accepted: 22.01 .2020

\section{How to Cite this Article:}

Rezaei Azandariani A

Pirdehghan A, Varmaghani M.

Evaluation of Multifidus Muscle

Atrophy in MRI Images of

Patients with Spinal Pain and its

Related Factors. Avicenna J Clin

Med. 2020; 26(4): 213-219.

DOI: $10.29252 /$ ajcm.26.4.213

\section{Abstract}

Background and Objective: Multifidus muscle which is one of the paraspinal muscles plays a key role in strengthening the spine and acts as inhibitory feedback in pain control. The present study aimed to evaluate the rate of multifidus muscle atrophy in Magnetic Resonance Imaging(MRI) images of patients with spinal pain.

Materials and Methods: In this cross-sectional study, 600 MRI images of patients with spinal pain (patients complaining of pain during clinical examination) referring to Besat Hospital of Hamadan within 2017- 2018 were selected by census method and evaluated for multifidus muscle atrophy based on its related variables. The obtained data were analyzed in SPSS software (version 16) at 95\% confidence level.

Results: The mean age of patients was reported as 46.16 years. In terms of gender, $46.5 \%$ of cases were male and $53.5 \%$ were female. The frequency of multifidus muscle atrophy was measured at $63.5 \%$ out of which $38.6 \%$, $43.6 \%$, and $17.8 \%$ were reported as grades one, two, and third, respectively. As evidenced by the obtained results, multifidus muscle atrophy and its degree showed a significant correlation with such variables as age, sex, body mass index(MBI), intense physical activity, duration of daily activities, duration and symmetry of pain $(\mathrm{P}<0.05)$.

Conclusion: The frequency of atrophy of multifidus muscle was reported to be high in the patients under study. Female gender, old age, high BMI, intense physical activity, duration of daily activities, duration of spinal pain and two-sided pain were recognized as independent variables associated with multifidus muscle atrophy.

Keywords: Magnetic Resonance Imaging, Multifidus Muscle, Spinal Pain 
dof: $10.29252 / \mathrm{ajcm} \cdot 26.4 .213$

\title{
بررسى ميزان آتروفى عضله مولتىفيدوس در تصاوير MRI بيماران مبتلا به درد ستون فقر ات و فاكتور هاى مرتبط با آن سن سن
}

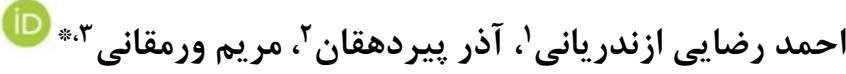

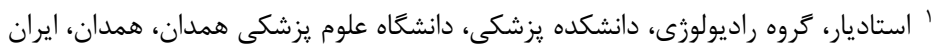

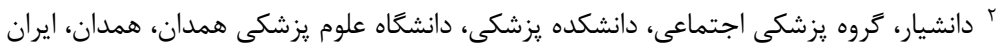

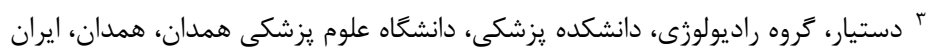
m.varmaghani1990@gmail.com : نويسنده مسئول: مريم ورمقانى، كروه راديولوزى، دانشكده يزشكى، دانشخاه علوم يزشكى همدان، همدان، ايران. ايميل :

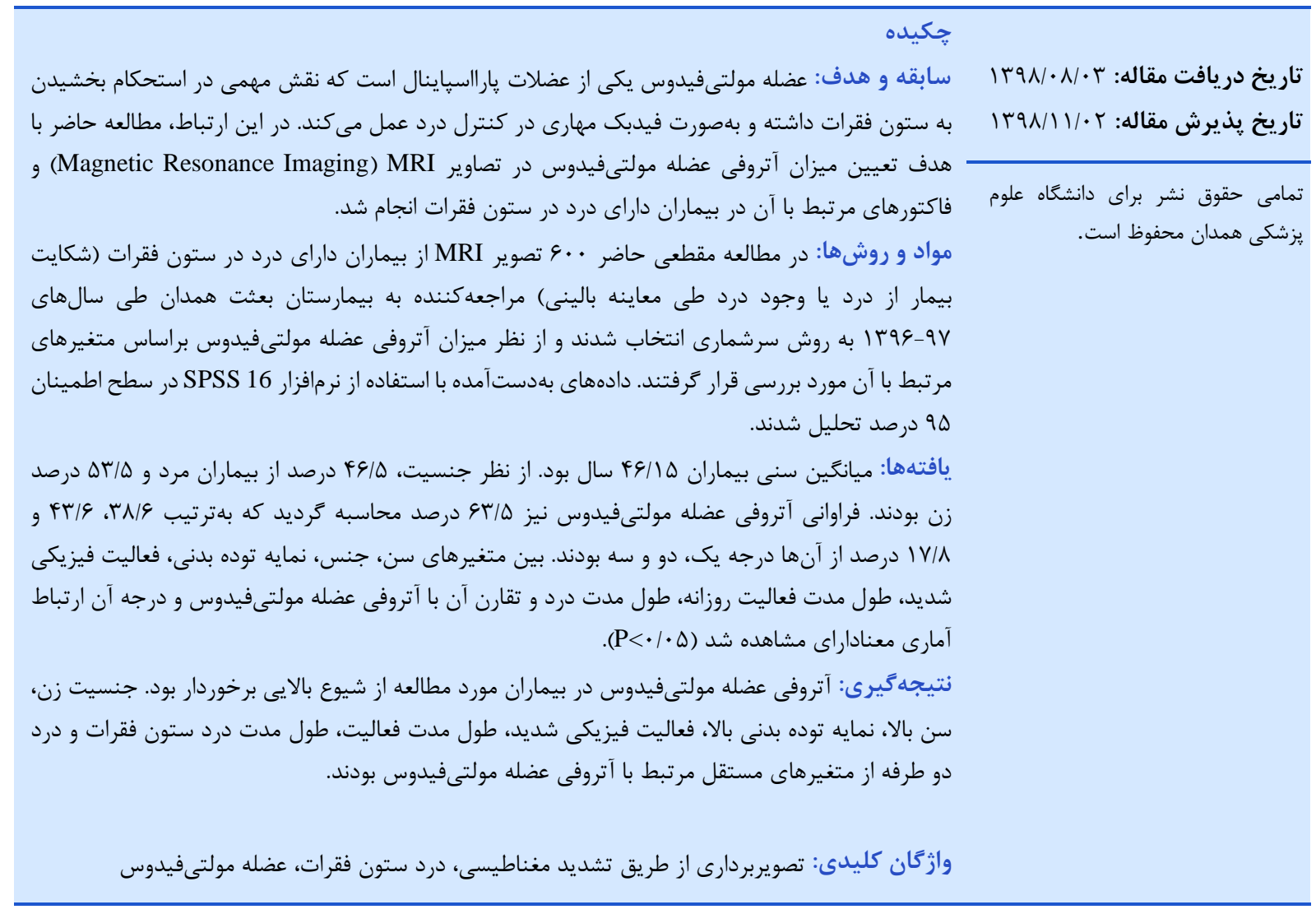

مقلدمه

نوروماسكولار شده و اين امر به نوبه خود موجب تغيير در

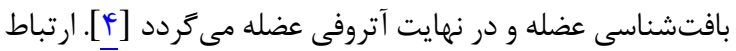

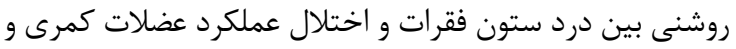

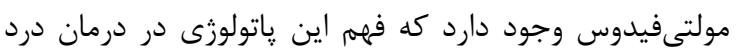

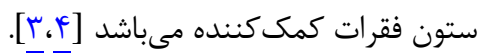

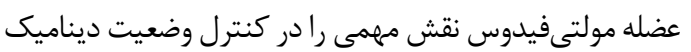

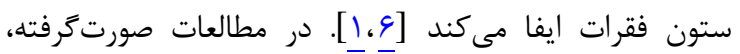

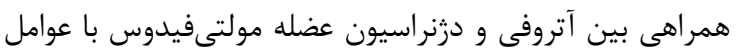

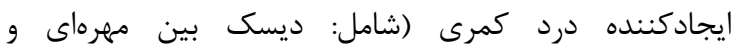

درد ستون فقرات از جمله ستون فقرات كمرى يك مشكل

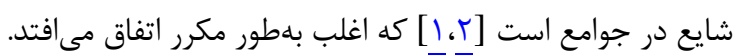

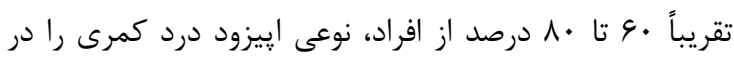

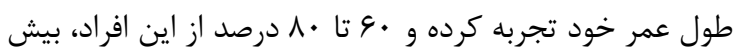

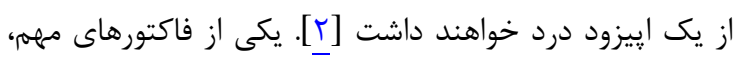

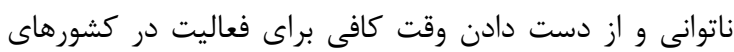

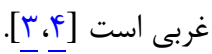

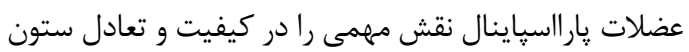
فقرات ايفا مىكنند [ه]]. كمردرد باعث تغيير در عملكرد 
يارامترهاى آزمايشَاهى از جمله PPD، Wright و 2ME و

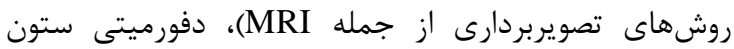
فقرات (تشخيص با استفاده از روشهاى تصويربردارى از جمله إنه (MRI كه تشخيص آن توسط آزمون توكسيكولوزى خون صورئ صورت

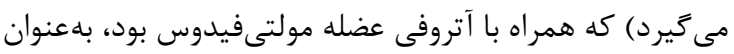

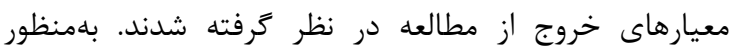

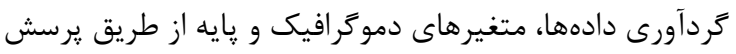

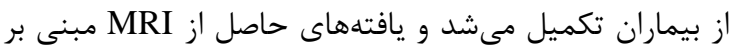

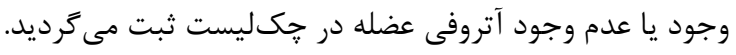

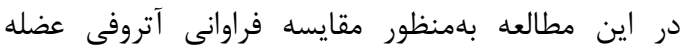

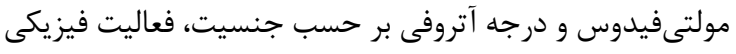

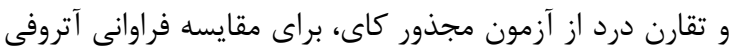

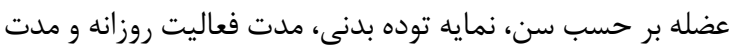

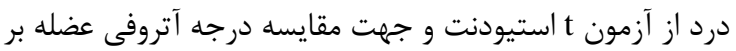

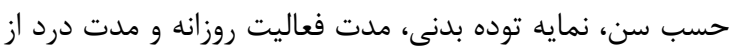

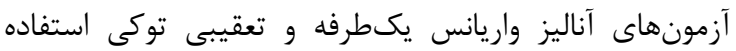

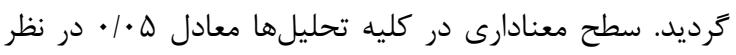

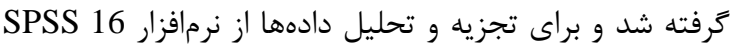
استفاده كرديد.

\section{كافته ها}

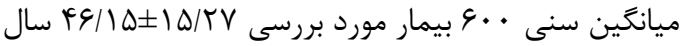

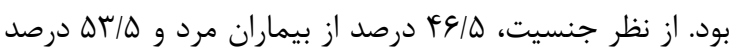

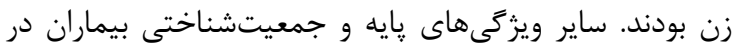
جدول ارائه شده است. در اين مطالعه شواهد آتروفى عضله مولتىفيدوس آدر در تصاوير ا IMRI نتايج بين فاكتورهاى مورد مطالعه شامل: جنس، وزن، فعاليت

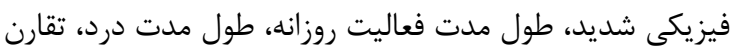

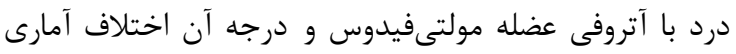

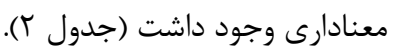

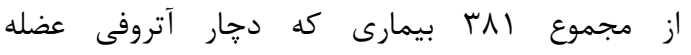

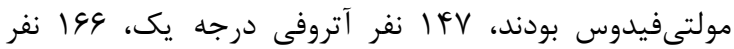

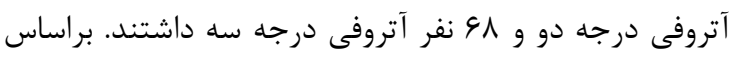

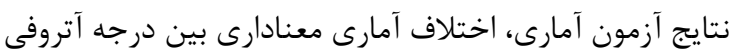

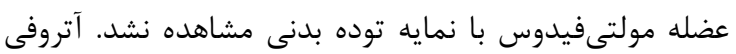
درجه دو و سه بهطور معنادارى در زنان بيشتر از مردان بود.

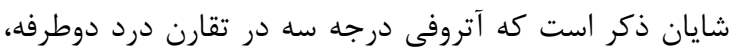
بيشتر و در فعاليت فيزيكى شديد، كمتر بود. بر مبناى نتايج

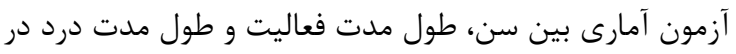

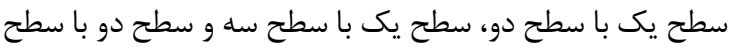

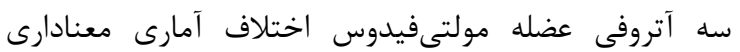
مشاهده شد (جدول r).
راديكولوياتى) نشان داده شده است [V]]. تغييرات پاتولوزيكى كه در عضله مولتىفيدوس اتفاق مىافتند مى توانند باعث عود علائم

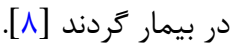
مطالعات هيستولوزيكال وجود ارتباط بين كاهش سايز عضله

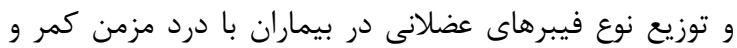

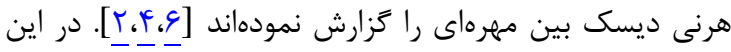

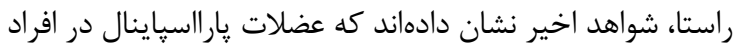

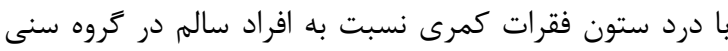

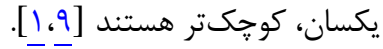

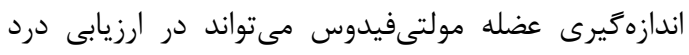

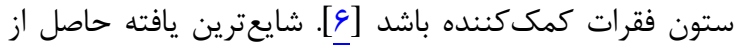

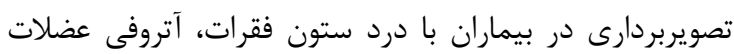
كمرى از جمله عضله مولتىفيدوس است [CSA [Y.Y.Y. و وانسيته عضلات پاراسياينال تحت (Cross Sectional Area) تأثير جند فاكتور از جمله سن، شرايط فيزيكى، رزيم غذايى، وزن

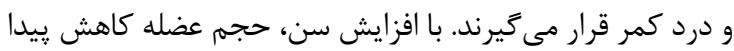

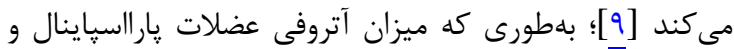

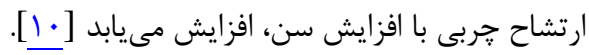

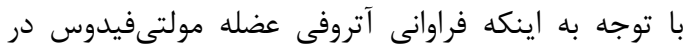
بيماران با درد ستون فقرات، قابلملاحظه بوده و اين عضله نقش آنش

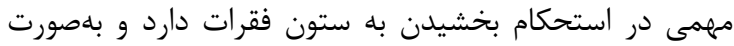

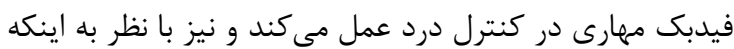

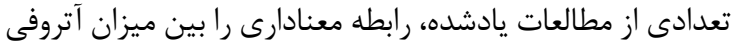

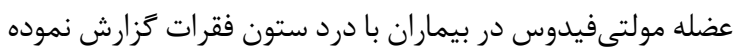

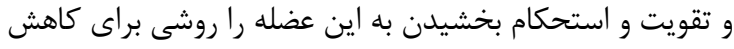

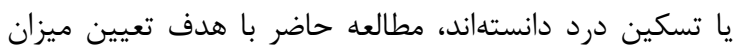

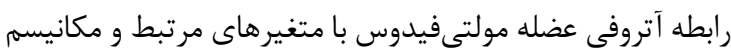

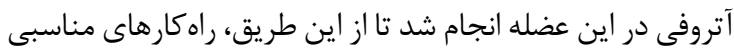
جهت كاهش يا تخفيف درد در بيماران مورد مطالعه ارائه تردد.

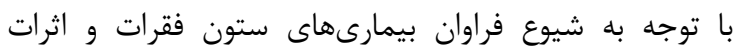

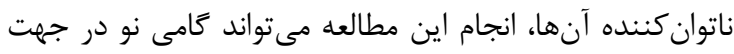
بهبود سلامت جامعه محسوب گردد.

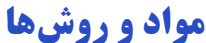
در مطالعه توصيفى- تحليلى حاضر كه به روش سرشمارى

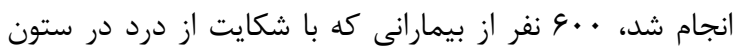

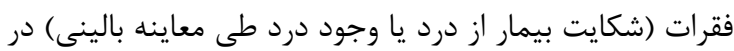

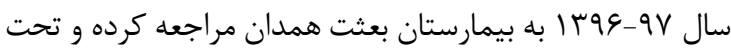
قرار گرفته بودند، پس از اخذ رضايت آكاهانه و شفاهى وارد مطالعه شدند. ابتلا به بيمارىهاى سيستميك نوروماسكولار شامل: نوروياتى، ميوياتى (تشخيص با انجام نوار عصب- سبدئل عضله)،

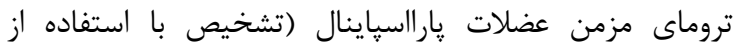
روشهاى تصويربردارى از جمله MRI)، بيمارىهاى عفونى يا يارينا

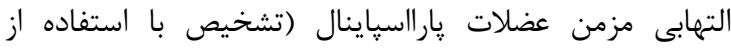


جدول ا: ويرَىى هاى پايه و جمعيتشناختى بيماران مورد مطالعه

\begin{tabular}{|c|c|c|c|}
\hline درصد & تعداد & سطوح متغير & متغير \\
\hline 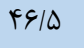 & rVq & مرد & \\
\hline$\Delta r / \Delta$ & Trt & 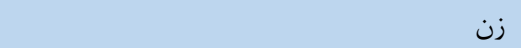 & بـس \\
\hline $9 / 1$ & (i) & ساختمانى & \multirow{7}{*}{ فعاليت فيزيكى شديد } \\
\hline $10 / V$ & 94 & دولتى & \\
\hline$r / \mu$ & re & بيمارستانى & \\
\hline$\checkmark$ & et & 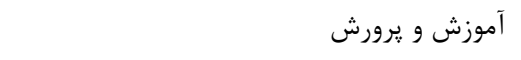 & \\
\hline $99 / \pi$ & rqv & ساير مشاغل & \\
\hline rq & rre & بله & \\
\hline q. & rat & خير & \\
\hline $1 / 1 /$ & $11 \pi$ & فرآوردههاى گوشتى، غلات و لبنى & \multirow{4}{*}{ رزيم غذايى } \\
\hline $\mid N / r$ & 11. & فرآوردههاى گوشتى، غلات، سبزيجات و حبوبات & \\
\hline$\Delta / \mu$ & rt & فرآوردههاى لبنى، سبزيجات و حبوبات & \\
\hline$\Delta V / \Delta$ & rFa & همه فرآوردهها & \\
\hline VF & per & 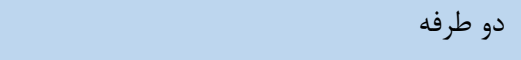 & \multirow{2}{*}{ تقارن درد } \\
\hline rq & 109 & يك طرفه & \\
\hline $1 N / \Lambda$ & $11 \pi$ & 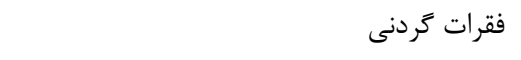 & \multirow{7}{*}{ محل درد } \\
\hline$r / \Lambda$ & IV & 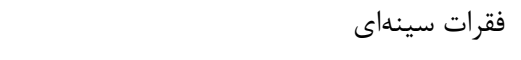 & \\
\hline$\Delta \varepsilon / T$ & rev & 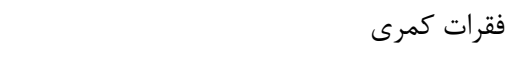 & \\
\hline $1 \cdot / V$ & gf & فقرات سينهاى و كمرى & \\
\hline$r / \Lambda$ & IV & سينهاى و كردنى & \\
\hline $9 / \pi$ & ऍ^ & تردنى و كمرى & \\
\hline$r / \mu$ & If & منتشر & \\
\hline QI & $r \cdot q$ & هرنى و بالجينَ ديسك ستون فقرات & \multirow{10}{*}{ علت درد } \\
\hline rt & Irv & بيمارى دزنراتيو ستون فقرات & \\
\hline$\cdot 1 \Lambda$ & $\Delta$ & بيمارى التهابى فقرات & \\
\hline 19 & 119 & 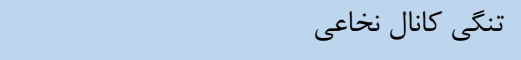 & \\
\hline$r \Delta$ & $I Q T$ & تروما و شكستكى مهره & \\
\hline 9 & c. & 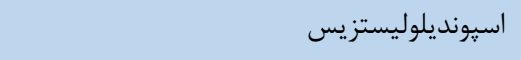 & \\
\hline rt & 194 & 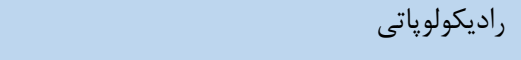 & \\
\hline هI & r. & 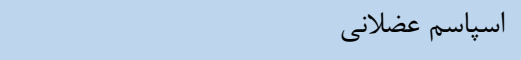 & \\
\hline $1 / \pi$ & $\wedge$ & 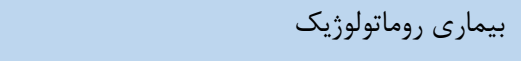 & \\
\hline$\cdot \pi$ & r & ساير علل & \\
\hline
\end{tabular}

جدول ك: توزيع فراوانى آتروفى عضله مولتىفيدوس در تصاوير MRI بيماران مورد مطالعه بر حسب متغيرهاى جمعيتشناختى، مدت و الكَى درد و

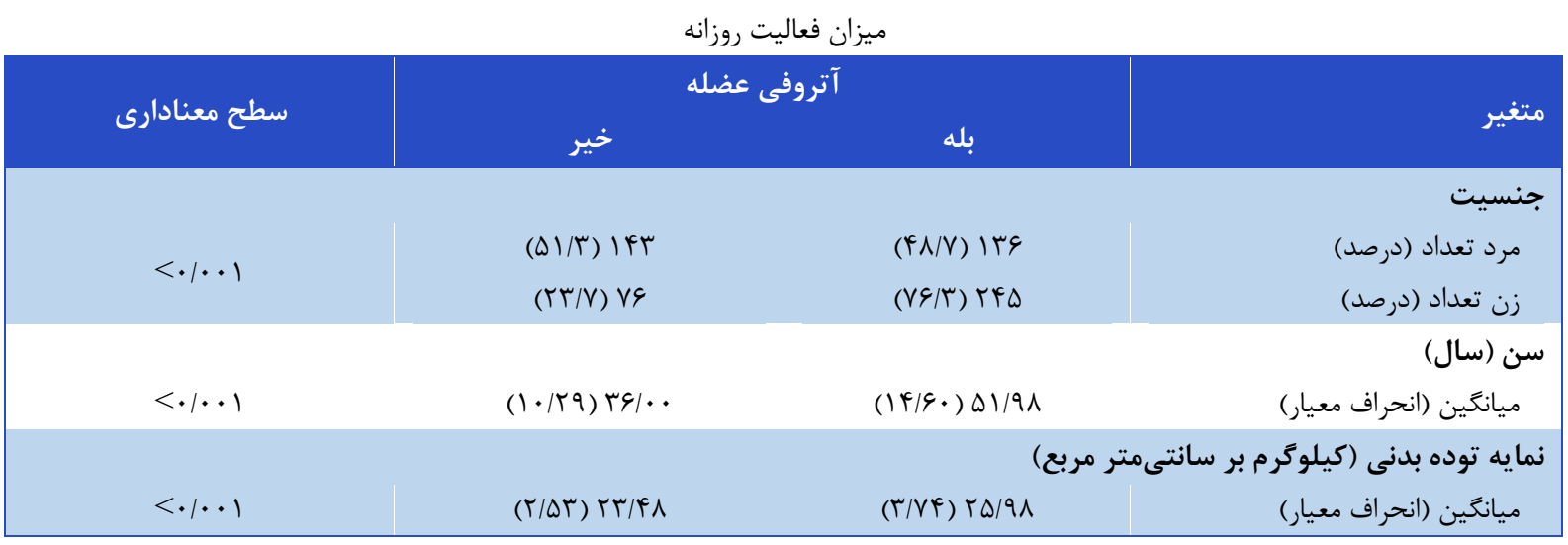




\begin{tabular}{|c|c|c|c|}
\hline & & & ادامه جدول r. \\
\hline$<\cdot|\cdot|$ & $\begin{array}{l}(r q / V) \vee \cdot \\
(F \cdot / q) \backslash \& q\end{array}$ & $\begin{array}{l}(V \cdot / r) \backslash 99 \\
(\Delta 9 / 1) r \mid \Delta\end{array}$ & خعاليت فيزيكى شديد \\
\hline$<\cdot 1 \cdot \cdot 1$ & $(\cdot / \wedge 9) 1 / / q 4$ & $(1 / M \Lambda) 1 \cdot / T r$ & طول ميانگين (انحراف معيار) \\
\hline$<\cdot|\cdot \cdot|$ & $(\cdot \mid q T) \cdot \mid \wedge \&$ & $(1 / 19) r / T \Delta$ & طول مدت درد (سال) \\
\hline$<\cdot|\cdot \cdot|$ & $\begin{array}{l}(F N / I) V D \\
(Y T / F) \backslash F F\end{array}$ & $\begin{array}{l}(\Delta / / q) \wedge) \\
(\Phi \vee / \varphi) r \cdots\end{array}$ & 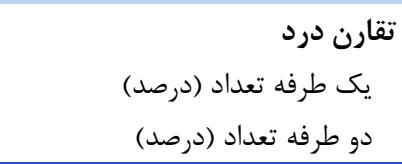 \\
\hline
\end{tabular}

جدول ب: توزيع فراوانى درجه آتروفى عضله مولتىفيدوس در تصاوير MRI بيماران مورد مطالعه بر حسب متغيرهاى جمعيتشناختى، مدت و الكَىى درد و ميزان فعاليت روزانه

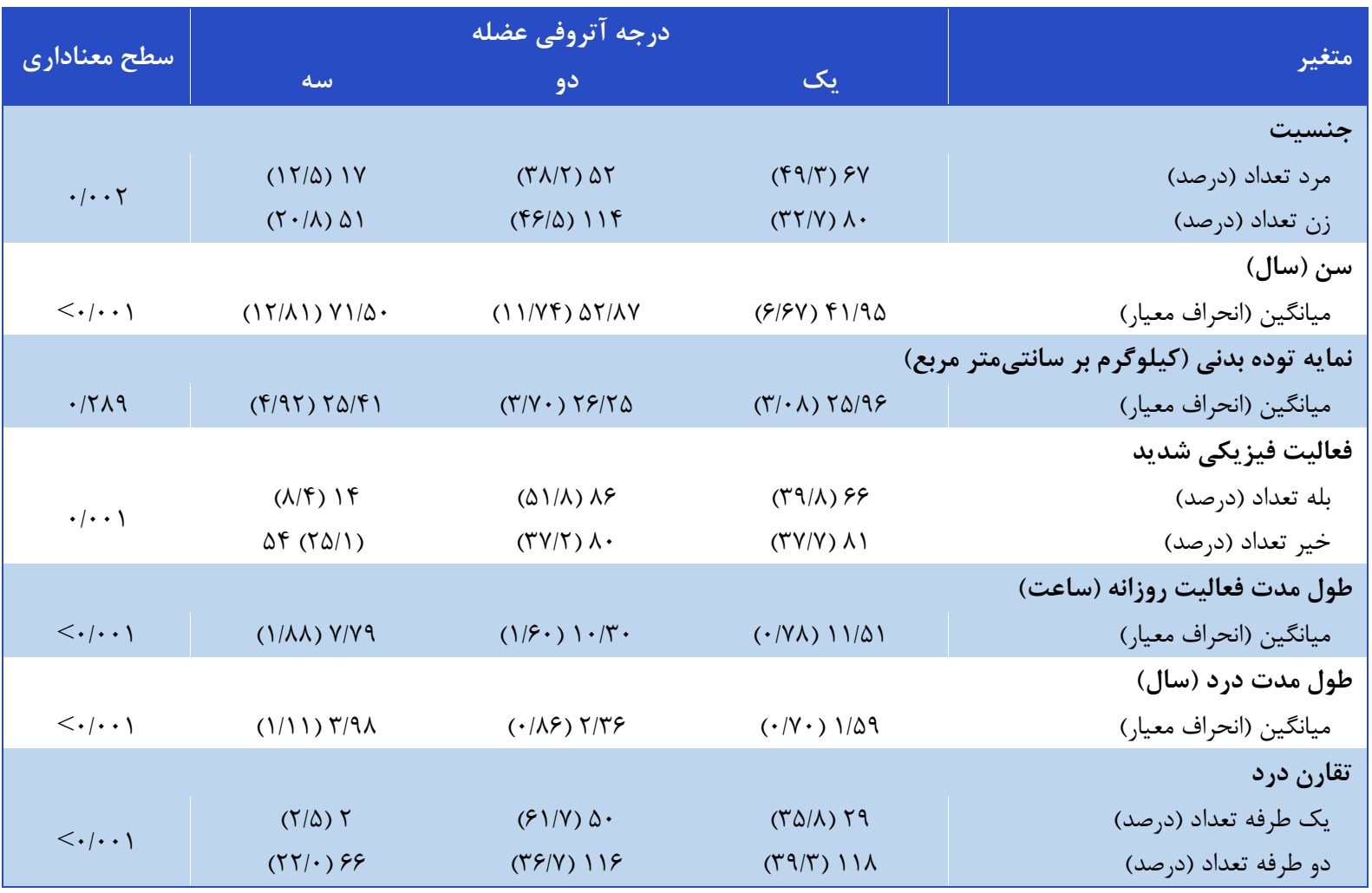

شد، از ميان · f بيمار با سابقه حداقل سه ماه احساس درد در

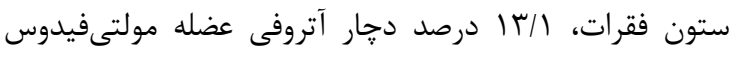

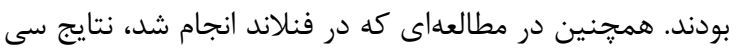

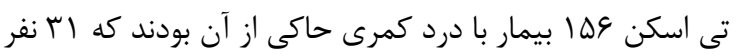

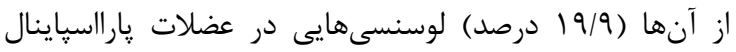

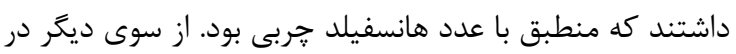

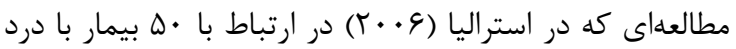

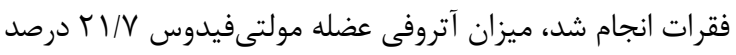

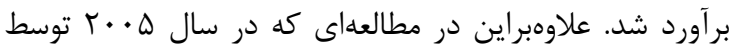
انجمن Radiological Society of North America) RSNA صورت گرفت، ها بيمار با درد مزمن كمرى مورد مطالعه قرار
در مطالعه حاضر فراوانى آتروفى عضله مولتىفيدوس براساس

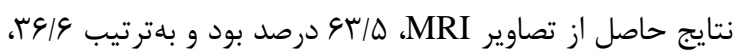

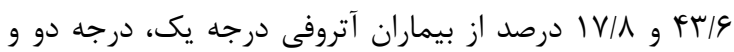

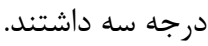
در مطالعات انجامشده در كشورهاى يونان، آمريكا، فنلاند و

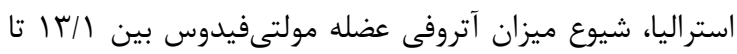

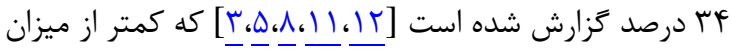

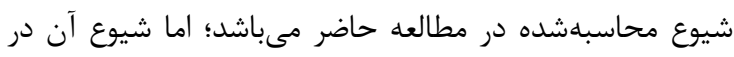

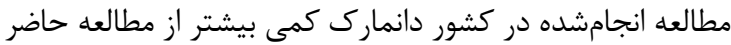
بود [f] در اين راستا در مطالعهاى كه در سال • • • د در يونان انجام 


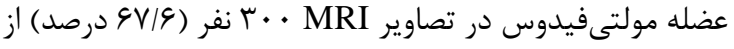

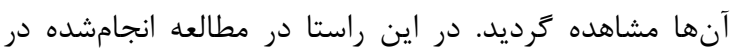

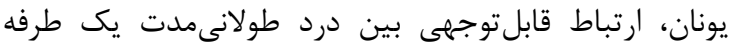

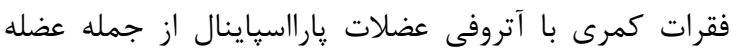
مولتىفيدوس وجود داشت [ه]] كه از اين نظر با نتايج مطالعه

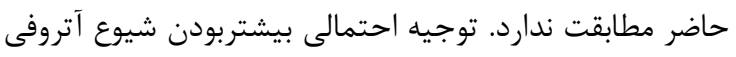
عضله مولتىفيدوس در بيماران با درد يك طرفه ستون فقرات

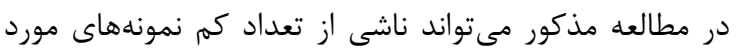

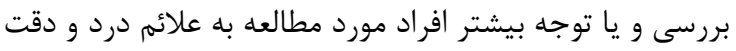
بيشتر در ييداكردن محل درد باشد.

\section{نتيجه تيرى}

با توجه به فراوانى بالاى آتروفى عضله مولتىفيدوس در تصاوير MRI بيماران با درد ستون فقرات مورد مطالعه مىتوان به نقش قابلتوجه اين عضله در كنترل درد ستون فقرات

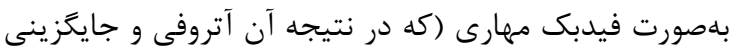
جربى در عضله ايجاد مىشود) يى برد و از طريق تقويت عضله

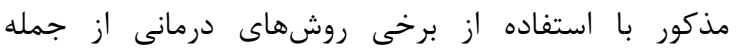

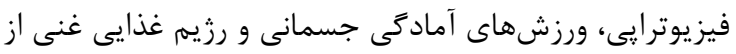

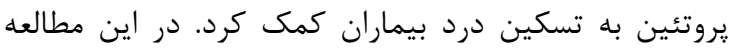

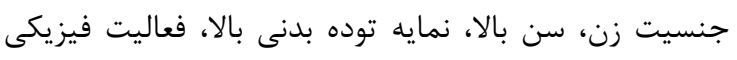

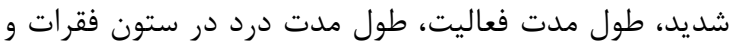

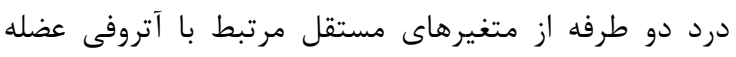
مولتىفيدوس بودند.

\section{تشكر و قلر دانى}

اين طرح مطالعاتى برگرفته از ياياننامه دوره دكترى

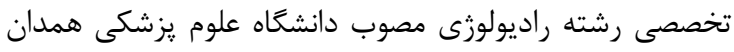

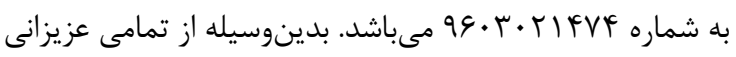

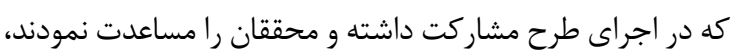

$$
\text { تقدير و تشكر مىشود. }
$$

تضاد منافع نتايج اين مطالعه با منافع نويسندگان در تعارض نمىباشد.

\section{ملا حظات اخلاقى}

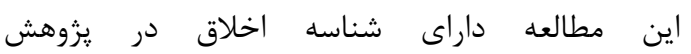
(IR.UMSHA.REC.1396.134) علوم يزشكى همدان بوده و با اخذ رضايت آكاهانه بيماران

$$
\text { (بهصورت شفاهى) انجام شده است. }
$$

سمه ذويسنان

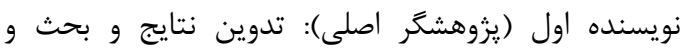

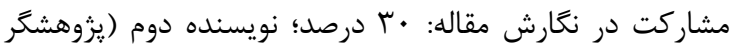

كَرفتند كه ع/شr درصد از آنها اينفيلتراسيون خربى در عضله مولتىفيدوس و لانخيسيموس داشتند. توجيه احتمالى كمتر بودن شيوع ميزان آتروفى عضله مولتىفيدوس در مطالعات انجام

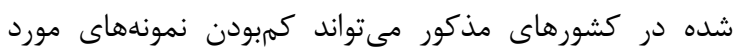

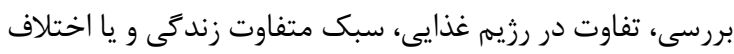

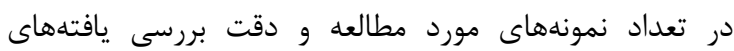
تصويربردارى باشد.

در مطالعه انجامشده در دانمارك، شيوع ميزان آتروفى عضله

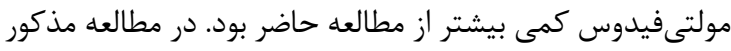

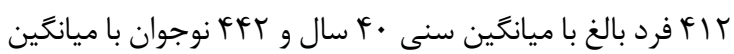

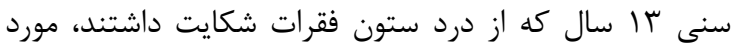

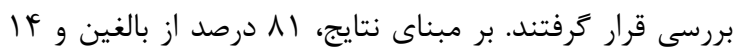

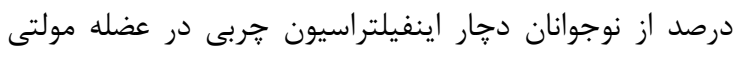

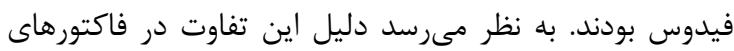

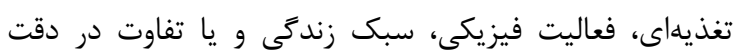
بررسى يافتههاى تصويربردارى باشد.

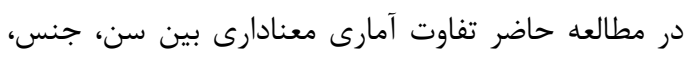

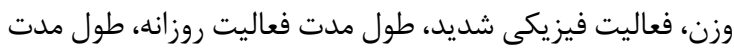

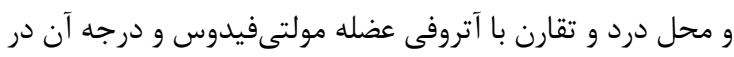
تصاوير MRI وجود داشت. در مورد فاكتور جنس بايد كَفت كه ده

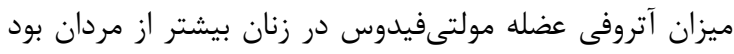

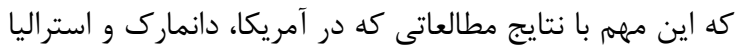

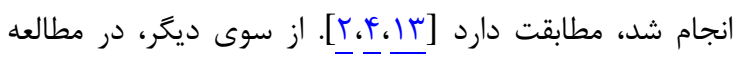
حاضر اختلاف آمارى معنادارى بين وزن با آتروفى عضله مولتى داري

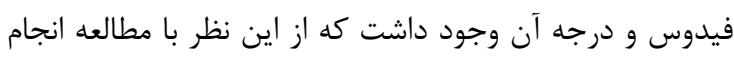

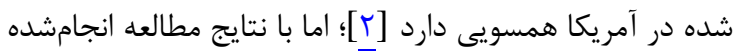

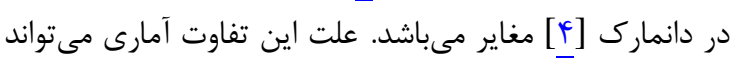

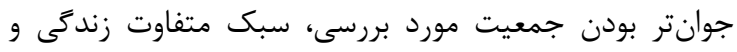
مسائل تغذيهاى آنها باشد. از سوى ديخر، در مطالعه حاضر اختلاف آمارى معنادارى بين باند

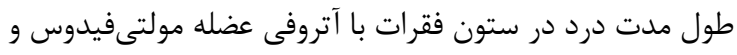

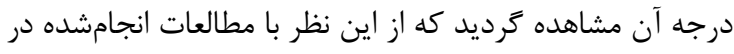

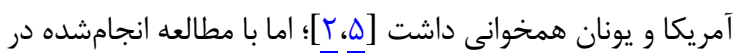

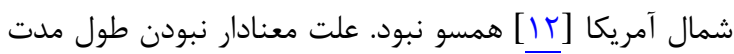

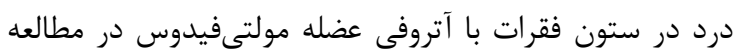

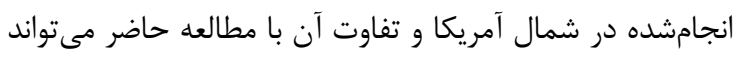

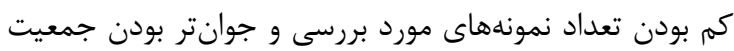

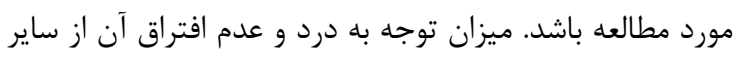

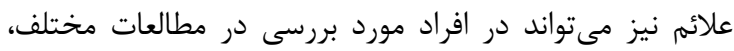

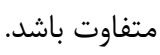
در بررسى تقارن درد در مطالعه حاضر، اختلاف آمارى باسد

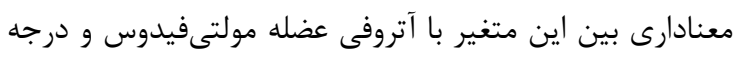

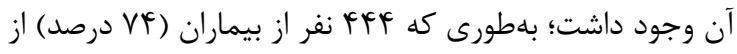

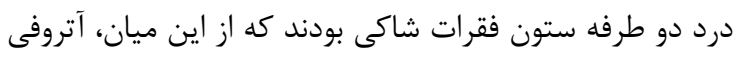




$$
\begin{aligned}
& \text { حمايت مالَى } \\
& \text { اين طرح از سوى معاونت تحقيقات و فناورى دانشعاه علوم } \\
& \text { يزشكى همدان حمايت مالى شده است. }
\end{aligned}
$$

اصلى): بازنخرى متون، تدوين روششناسى، تحليلگر آمارى طرح

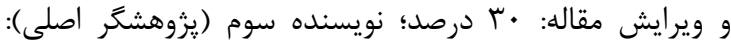

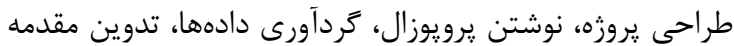

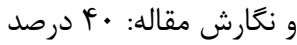

7. Tabaraee E, Ahn J, Bohl DD, Phillips FM, Singh K. Quantification of multifidus atrophy and fatty infiltration following a minimally invasive microdiscectomy. Int J Spine Surg. 2015;9:25. PMID: 26196032 DOI: 10.14444/2025

8. Hides JA, Richardson CA, Jull GA. Multifidus muscle recovery is not automatic after resolution of acute, firstepisode low back pain. Spine. 1996;21(23):2763-9. PMID: 8979323 DOI: 10.1097/00007632-199612010-00011

9. Kalichman L, Hodges P, Li L, Guermazi A, Hunter DJ. Changes in paraspinal muscles and their association with low back pain and spinal degeneration: CT study. Eur Spine J. 2010;19(7):1136-44. PMID: 20033739 DOI: 10.1007/ s00586-009-1257-5

10. Hadar H, Gadoth N, Heifetz M. Fatty replacement of lower paraspinal muscles: normal and neuromuscular disorders. AJR Am J Roentgenol. 1983;141(5):895-8. PMID: 6605058 DOI: 10.2214/ajr.141.5.895

11. Laasonen EM. Atrophy of sacrospinal muscle groups in patients with chronic, diffusely radiating lumbar back pain. Neuroradiology. 1984;26(1):9-13. PMID: 6234476 DOI: $10.1007 / \mathrm{bf} 00328195$

12. Mengiardi B, Schmid MR, Boos N, Pfirrmann CW, Brunner F, Elfering A, et al. Fat content of lumbar paraspinal muscles in patients with chronic low back pain and in asymptomatic volunteers: quantification with MR spectroscopy. Radiology. 2006;240(3):786-92. PMID: 16926328 DOI: 10.1148/radiol. 2403050820

13. Hides J, Gilmore C, Stanton W, Bohlscheid E. Multifidus size and symmetry among chronic LBP and healthy asymptomatic subjects. Man Ther. 2008;13(1):43-9. PMID: 17070721 DOI: 10.1016/j.math.2006.07.017 